\title{
Wavelet-Alienation Coefficient based Protection of Distribution System
}

\author{
Durgaprasad Bandaru, Abdul Gafoor Shaik
}

\begin{abstract}
Growth enhances the complexity in control of distribution networks which are progressing towards the vision of smart grids. Inclusion of non-conventional resource power generators affects in magnitude and flow directions of faults in the distribution system there by posing challenges towards protection of distribution system.. A wavelet and alienation coefficients based algorithm described in this paper for electrical distribution network protection which is also connected with wind farm. The algorithm takes the current samples at selected nodes of the wind farm connected distribution system. From the collected samples of the current signals approximation coefficients are extracted using wavelet technique. A moving half cycle window is used to obtain alienation coefficients of the current signals which were approximated by wavelet technique. Using the WT (Wavelet transform) decomposition on the currents measured at selected nodes approximation coefficients are computed, which are used for acquiring the alienation coefficients to fault classification and identification. MATLAB Simulink is used for simulation of modified IEEE 13 bus test feeder system.Effectiveness of proposed technique examine for all possible shunt faults at every bus of test feeder system. Also the effect of wind speed variations and location of wind farm connection conditions are tested to evaluate the reliability of the technique.
\end{abstract}

Keywords-IEEE 13 Bus test feeder, Distribution network, wind based DG, protection, wavelet, alienation coefficients.

\section{INTRODUCTION}

Scarcity in conventional resources and concerns on global warming conditions has routed the generation of electrical power from non-conventional sources. Wind energy based power generation takes huge portion among the non-conventional resources. Advancements and improvements in control techniques of wind power based electrical generators enhanced the reliability electrical power by wind power[1]

In a wind farm connected distribution system there an increment in fault current magnitude and DG presents an extra wellspring of issue current, may build the absolute fault level inside the system, while conceivably modifying the size and bearing of the deficiency flows seen by explicit security transfers. The dedication of one single producing unit is commonly not tremendous, yet the all-out effect of many creating units can essentially influence issue flows and impact the movement of the overcurrent assurance arrange [2].

Revised Manuscript Received on September 22, 2019

* Correspondence Author

Durgaprasad Bandaru, Research Scholar, Acharya Nagarjuna University, Guntur, India durga206@gmail.com

Abdul Gafoor Shaik, Associate professor, Department Electrical Engineering, Indian Institute of Technology Jodhpur, India, saadgafoor@iitj.ac.in
Distribution network which works with moderate voltage values, facing difficulties in charge, insurance and activity when renewable source power generators associates [4,5]. Problems of incorporated wind power based electrical generators to appropriation frameworks are inspected in different authors examines [4,9]. wind power based electrical generators composed of dissemination frameworks were in like manner contribute shortcoming flow gives a mind boggling sway on warm limit and security hardware $[5,6]$. Along these lines, insurance procedures which are used for power framework security not light about wind turbine generators are unsuitable about need in deficiency conditions [10].Hence an explanation is required to determine every one of the issues, paying little mind to area, capacity and count of wind power based electrical generators group.

The effect of DG and resolutions have been exhibited in [11] An adoptable protection scheme presented by authors at [12]-[14] the creators recommend utilization of limiters of fault current (LFC), the researchers of [14]-[16] recommend utilizing versatile protection scheme. In [14] and [15] authors proposed a separate protection settings for with DG and without DG, In [16] authors recommended a plan to change overcurrent protection setting by dependent on the shortcoming magnitude and the DG affiliation stature. An answer which accommodates isolate assignment recommended in [10] and [17], specialists display way of clear flexible overcurrent assurance plot through two locale together-one for lattice related and isolation technique for movement may deal with the issue. The specialists $[3,20]$ showed that proximity DG impacts the selectivity, affectability and operational events of current setting relays. Security methodologies, issue recognizing evidence strategies are discussed in [21-27].Fault discovery and arrangement plans utilizing wavelet proposed by S. A. Gafoor, et al [6,30-32]. Masoud.M and et al. exhibited a distance coefficients system for security of transmission lines [7].

The majority of recommend flexible over current protection schemes in research study appear to focus on the answer for a particular security execution issue and ignores different parts of future systems that may affect execution. In this manner, these plans are to some degree restricted, as later on. Wavelet and signal correlation based method refers dissect state of abnormal condition proposed in this paper. This procedure is neither relies upon size of the framework nor fault current extent. In this major part information extricated from the measured signals by utilizing wavelet instrument and likeness of wave structures cycle by cycle acquired utilizing alienation coefficients, which makes the 
method strong in recognizing every single anomalous state of the system. Here onwards papers divided as, alienation and wavelet based strategy in segment -2 , Details of used network in segment 3, fault identification and categorization in segment 4, contextual analyses in segment 5 and end comments in segment 6 .

\section{WAVELET - ALIENATION COEFFICIENTS}

\section{A.WAVELET TRANSFORM:}

In separation of transient portion in the signals Wavelet Transform (WT) is a capable method. Diverse changes like DFT, FFT are examines the sign in just recurrence zone, while in wavelet uses different windows for different frequencies. Wavelet can be picked with altogether charming recurrence and time information. Wavelet transform estimations depend on, the scrabbling function $\Phi(\mathrm{p})$ and the wavelet function $\square$ (p)

$$
\begin{aligned}
& (p)=\sqrt{ } 2 \square h_{k}(2 p-k) \\
& \square(p)=\sqrt{ } 2 \square g k \Phi(2 p-k)
\end{aligned}
$$

The discrete successions $h_{k}$ and $g_{k}$ speak to discrete channels that comprehend every condition, wheregk $=(-1) \mathrm{k} h N-1-\mathrm{k}$ Such a significant number of sorts of wavelets are existing, as symlet, $d b$ (Daubachies), coif, haar and so on. Decision of mother wavelet changes with application.

\section{B. ALIENATION COEFFICIENTS}

Two signal $\mathrm{x} 1$ and $\mathrm{x} 2$ alienation coefficients are determined by expression as given.

$$
A=1-r^{2}
$$

' r' stands for the correlation coefficients of the two signals

$$
r=\frac{N_{S}\left(\sum x 1 x 2\right)-\left(\sum x 1\right)\left(\sum x 2\right)}{\sqrt{\left[N_{S} \sum x 1^{2}-\left(\sum x 1\right)^{2}\right]\left[N_{S} \sum x 2^{2}-\left(\sum x 2\right)^{2}\right]}}
$$

Estimation of alienation coefficients using approximation coefficients as follows.

$$
A_{\text {ap }}=1-r_{a p}^{2}
$$

Where $r_{a p}$ refers to successive half cycles correlation between $\mathrm{x} 1_{\text {ap },} \mathrm{x} 2_{\text {ap }}$ at similar instants.

$$
r_{a p}=\frac{N_{s}\left(\sum X 1_{a p} X 2_{a p}\right)-\left(\sum X 1_{a p}\right)\left(\sum X 2_{a p}\right)}{\sqrt{\left[N_{S} \sum X 1_{a p}^{2}-\left(\sum X 1_{a p}\right)^{2}\right]\left[N_{S} \sum X 2_{a p}^{2}-\left(\sum X 2_{a p}\right)^{2}\right]}}
$$

$N_{s}$ is half cycle window samples

$\mathrm{X} 1_{\text {ap }}=$ approximation coefficients of half cycle $\mathrm{X} 1$ at $\mathrm{t}_{0}$

$\mathrm{X} 2_{\text {ap }}=$ approximation coefficient of half cycle $\mathrm{X} 2$ which is with same polarity at previous cycle same time instant.

Two signals change is computed by alienation and obtained coefficients are known as alienation coefficients. It extends somewhere in the range of ZERO and ONE.
Approach of computation of alienation coefficients using half cycle window is represented in figure1.where $\mathrm{W}_{-1}$ previous window and $\mathrm{W}_{0}$ is present window of same polarity.
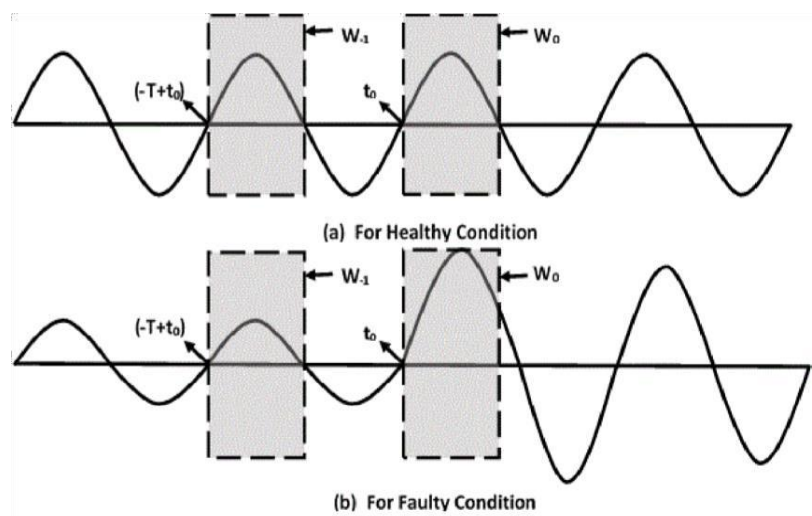

Fig. 1. Half cycle window comparison for alienation coefficients.

\section{Proposed wavelet alienation coefficients technique:}

Three stage current sign are assessed at B650 and B680 hubs are made with an examining recurrence of $1920 \mathrm{~Hz}$. Coming up next are steps connected with the proposed arrangement.

- Wavelet decay connected on got three stage differential current examples by mother wavelet 'db8'.

- Using mother wavelet 'db8' approximation coefficients are computed.

- Alienation coefficients (Aa) are computed by looking at the surmised coefficients got at present window (W0), with those of past window (W-1) of same extremity as appeared in figure 1 .

- compare the estimations of Aa with limit esteem, under ordinary situations, the estimation of Aa stays ' 0 '. In occasion at disturbance or unsettling influence may limited worth and above edge.

For flaws including with two lines like (phase to phase) ph-ph and (phase to phase and ground) ph-ph-g.it is difficult to isolate with just guess coefficients that which one is ph-ph and which one is ph-ph-g. To defeat this type of issue, current Io computed as follows.

$$
I_{0}=\frac{I_{a}+I_{b}+I_{c}}{3}(7)
$$

For the faults involved with ground zero sequence current is 0.1 times of pahse current (Iph). The procedure shown in figure(2) indicates the computation processes of technique. 


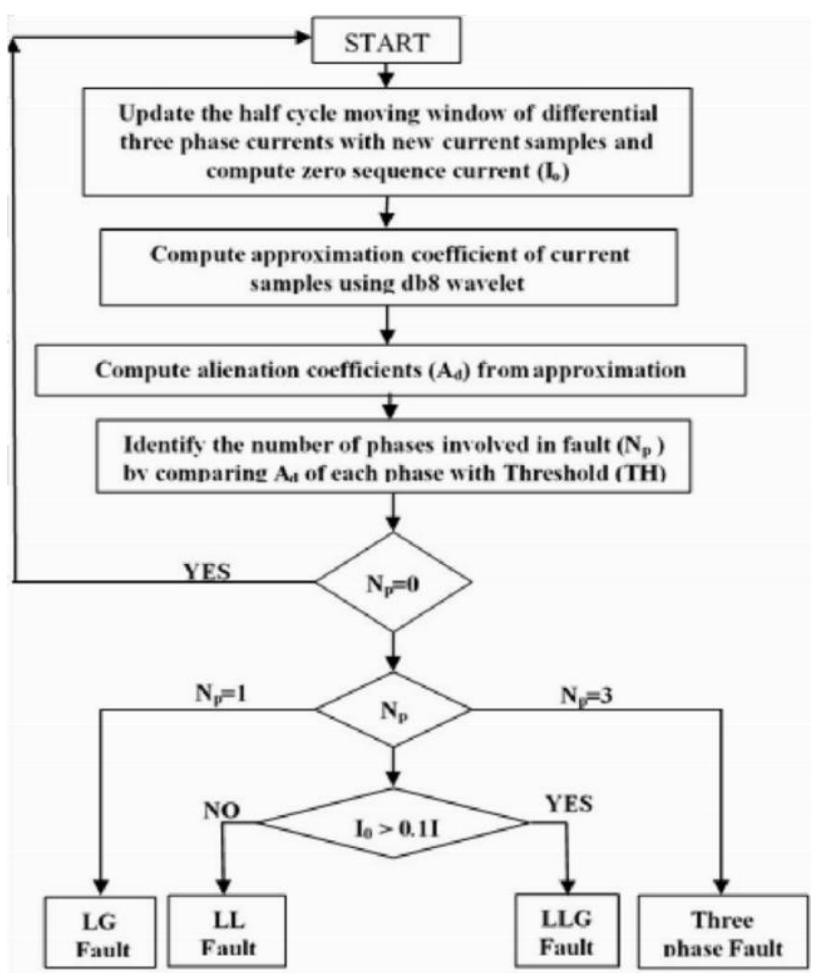

Fig 2: proposed technique flow chart

\section{TEST SYSTEM DESCRIPTION}

Test system considered for study shown in figure 3 . Distribution network of 13 bus system is modified for the simulation study. Considered system is balanced three phase three wire system. Voltage of grid node maintained at $115 \mathrm{kv}$ at $\mathrm{B} 650$ and wind farm of $9 \mathrm{MW}$ is included to the network at B680.Details of the distribution network tabulated in Table1.

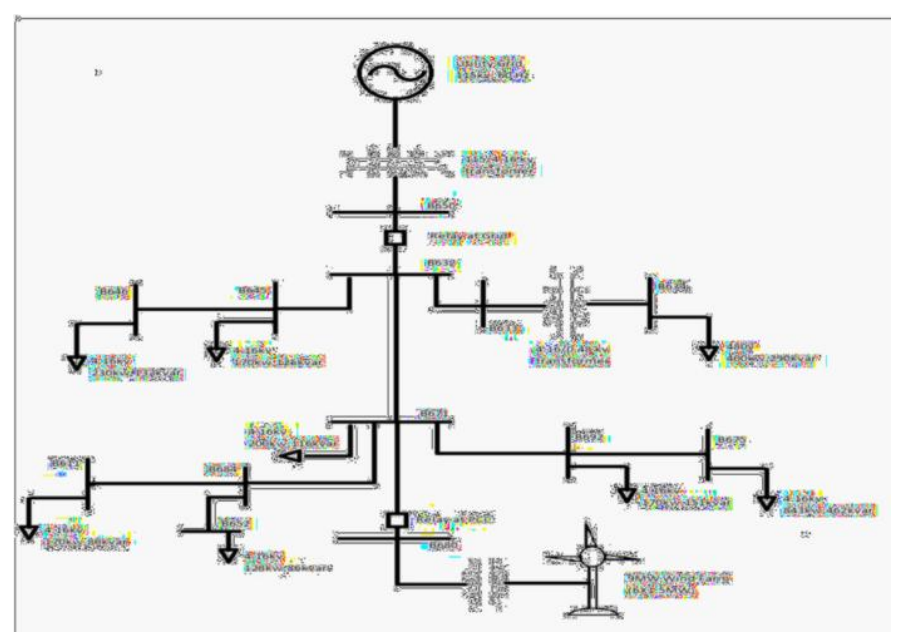

Fig. 3.IEEE13 network with wind farm

TABLE I TEST FEEDER SYSTEM DATA

\begin{tabular}{|c|c|c|c|}
\hline S.No & $\begin{array}{c}\text { System } \\
\text { parameter }\end{array}$ & Bus node & Rating \\
\hline 1 & Grid node & B650 & 60Hertz , 115kilo volts \\
\hline 2 & $\begin{array}{c}\text { DG side } \\
\text { transformer }\end{array}$ & B680 & $\begin{array}{c}10.5 \text { Mega Volt Amp } \\
4160 / 575 \text { Volts } \\
\text { star } \\
\text { ground-Delta }\end{array}$ \\
\hline 3 & Wind based & B680 & $\begin{array}{c}\text { 9 Megawatts } \\
\text { DG }\end{array}$ \\
& & & $\begin{array}{c}\text { 1.5Megawatts each }) \\
575 \text { volts }\end{array}$ \\
\hline
\end{tabular}

\section{DETECTION ANDCLASSIFICATIONOF FAULTS}

Considered test system simulated for 10-cycles time, In which initial 5 cycles under system, normal condition and remaining 5 cycles under abnormal condition. At every single bus of test feeder network, each of the ten shunt faults created. At every bus of the distribution network faults are simulated to set the threshold value(TH).

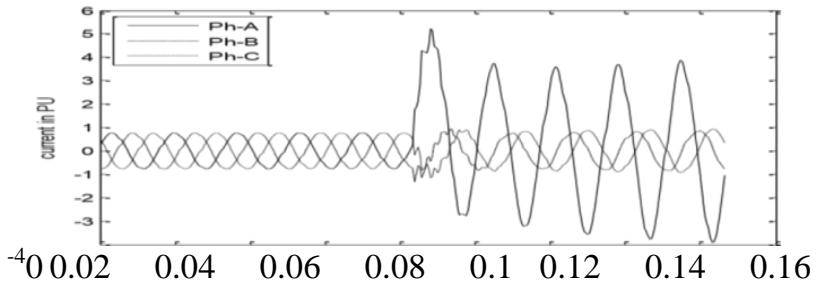

Time in Sec Time in Sec
At test feeder node B684 simulation done for phase to ground fault (ph-g) fault. Measured three phase differential currents are decomposed for approximation coefficients as shown in Fig.4(a), at B650 and B680. Form the obtained approximation coefficients, alienation coefficients are computed and compared with threshold value (TH) as presented in Figure.4(b). From The Figure.4(b) it is clearly observed that a phase to ground (ph-g) occurred on the system and it also reveals that fault occurred on phase-A.

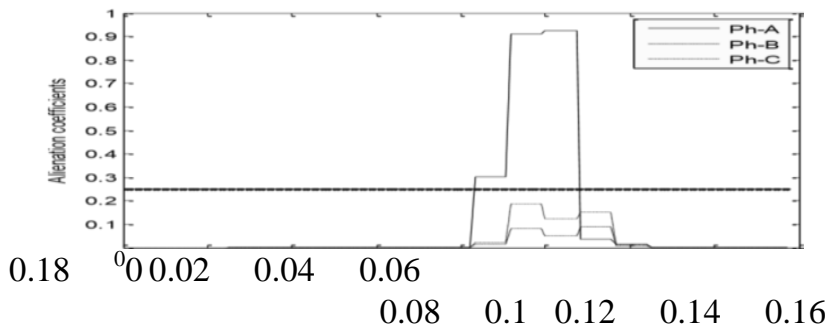

Fig 4(a) approx coefficients of 3-ph currents for ph-g fault at node B684

For ph-g fault at B684 alienation coefficients 
At test feeder node B684 a 3-ph(LLLG) shunt fault is simulated. Measured three phase differential currents are decomposed for approximation coefficients as shown in Fig.5(a), at B650 and B680. Form the obtained approximation coefficients, alienation coefficients are computed and compared with threshold value (TH) as presented in Fig.5(b). From Fig.5 (b) it is clearly observed that a 3-ph fault (LLLG) occurred on the system and it also reveals that fault occurred on all three phases.
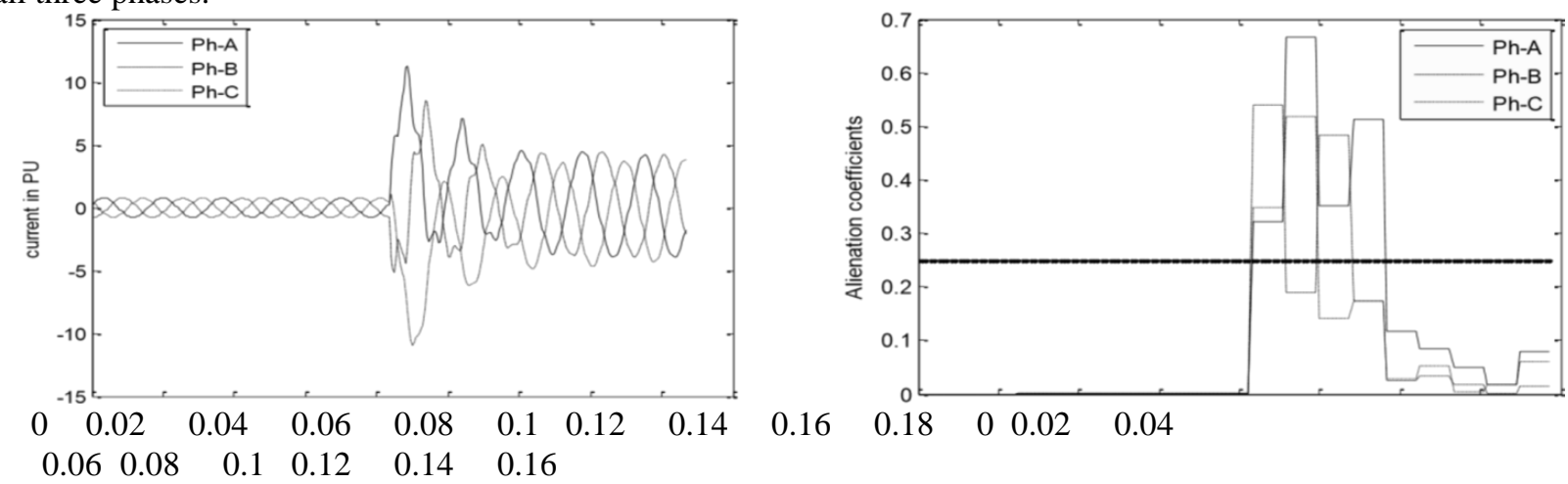

Time in Sec Time in Sec

Fig 5(a): differential currents for ph-ph-ph-g at B684 node

Fig .5(b): Alienation coefficients for ph-ph-ph-g at B684 node At test feeder node B684 a line to line (LL) fault is simulated. Measured three phase differential currents are decomposed for approximation coefficients as shown in Fig.6(a), at B650 and B680. Form the obtained approximation coefficients, alienation coefficients are computed and compared with threshold value (TH) as presented in Fig.6(b). From The Fig.6 (b) it is clearly observed that a ph-ph-g occurred on the system and it also reveals that fault occurred on phase-A and phase-B.
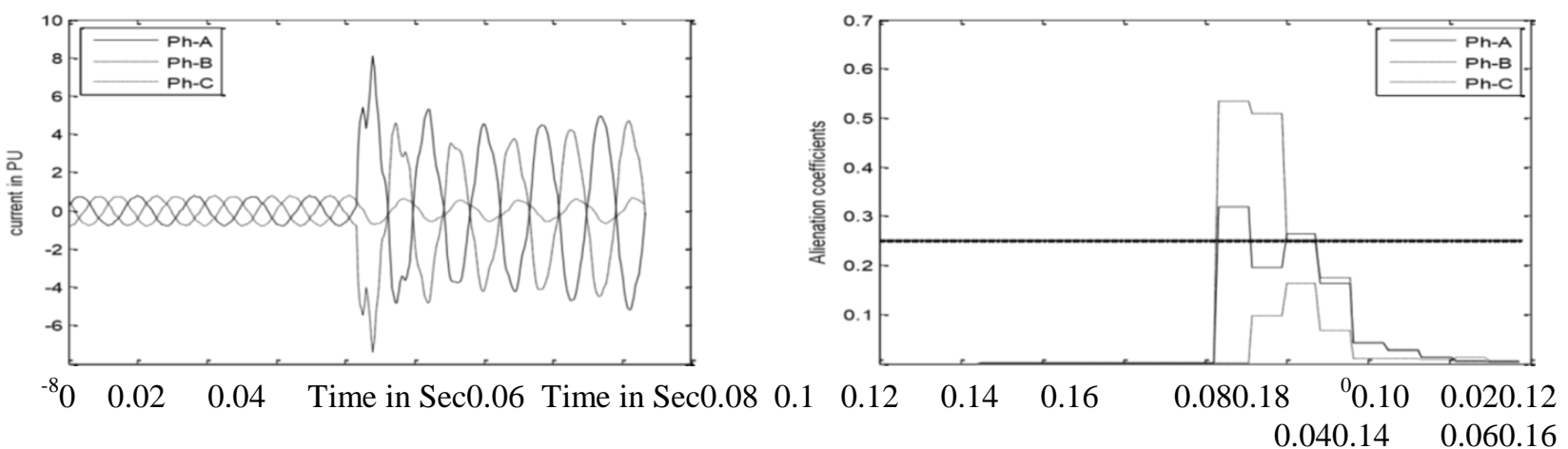

Fig 6(a) approx coefficients of 3-ph currents for ph-ph fault at node B684Fig 6(b) For ph-ph fault at B684 alienation coefficients

At test feeder node B684 a double to ground fault is simulated. Measured three phase differential currents are decomposed for approximation coefficients as shown in Fig.7(a), at B650 and B680. Form the obtained approximation coefficients, alienation coefficients are computed and compared with threshold value (TH) as shown in Fig.7(b). From The Fig.7 (b) it is clearly observed that a double line fault occurred on the system and it also reveals that fault occurred on phase-A and phase-B. From figures 6(b) and 7(b) it clearly observed that both figures indicates

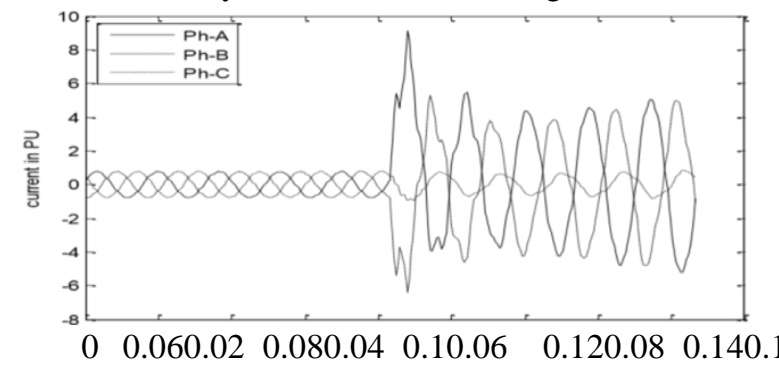

occurred fault is in between two phase but it is not clearly discriminates that occurred fault is ph-ph or ph-ph-g fault. Hence alienation coefficients alone unable to make the discrimination between the LL and LLG faults. In general ground faults have the neutral current which is $10 \%$ of the phase currents. By computing the ground current and comparing as shown in the figure. 7(c). clearly it is represented that LLG fault has appreciable ground current compare to LL fault which was used for discrimination of ph-ph and ph-ph-g faults.

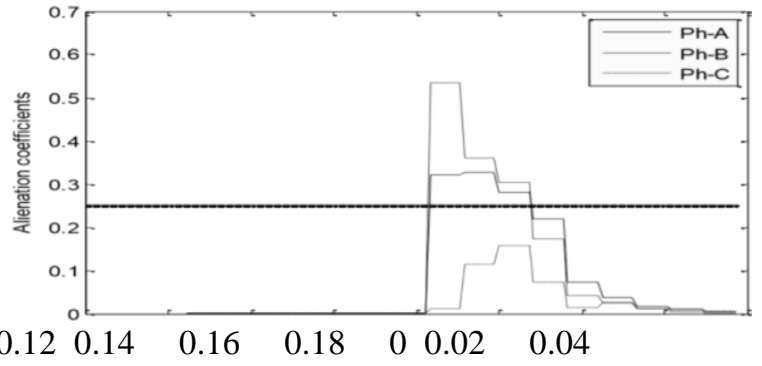

Time in Sec Time in Sec 


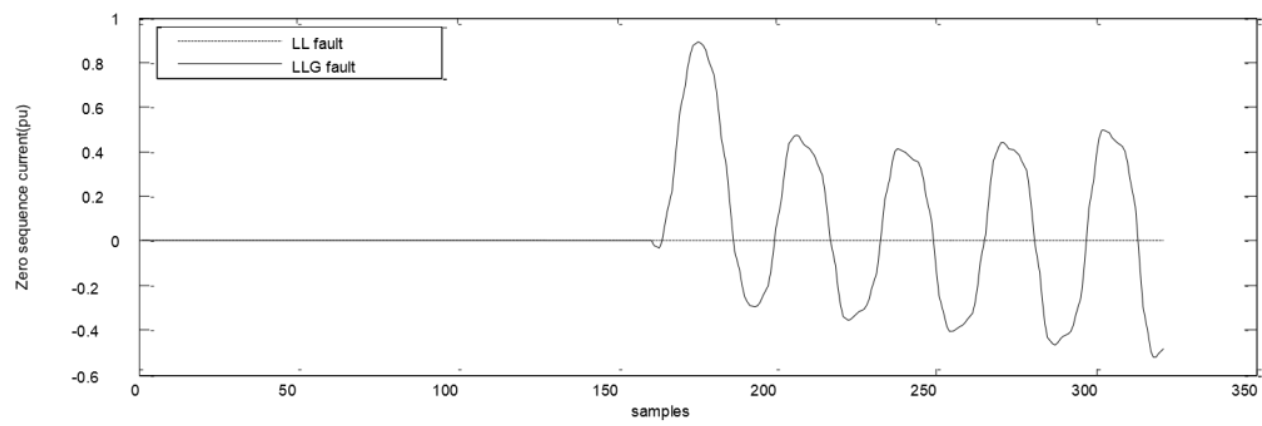

Fig 7(c): $\mathrm{I}_{0}$ for ph-ph and ph-ph-g fault

Fig.7(c), it is clear that the $\mathrm{I}_{0}$ current is more for ph-ph-gcompare to ph-ph shortcoming. In this manner, ph-ph deficiencies can be recognized from ph-ph-gblames by contrasting their flows $\mathrm{I}_{0}$.

\section{CASE STUDIES}

\section{A. VARIATION OF FAULT LOCATION:}

Disturbance occurring bus location will alter level of current value and current flow directions, hence effectiveness of proposed algorithm also need to test for different fault locations. Fig. 8 outlines variety of fault files of three stages for various shunt deficiencies. From Fig. 8a it is apparent that deficiency list of ph-' $a$ ' is constantly more noteworthy than

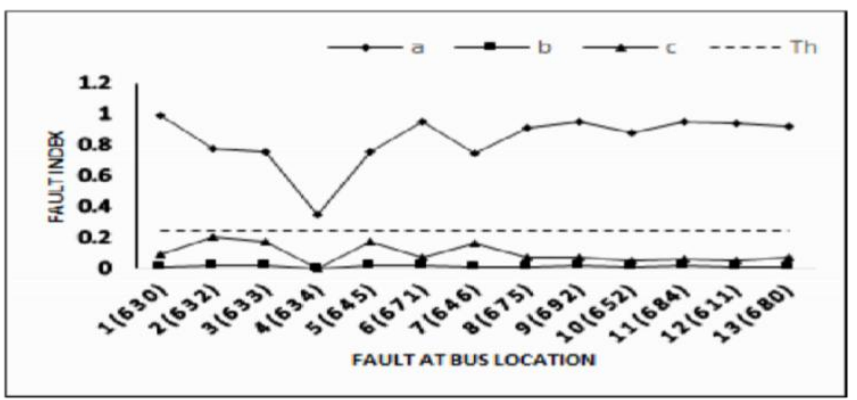

Fig.8(a): ph-'a' to ground fault index for various fault nodes

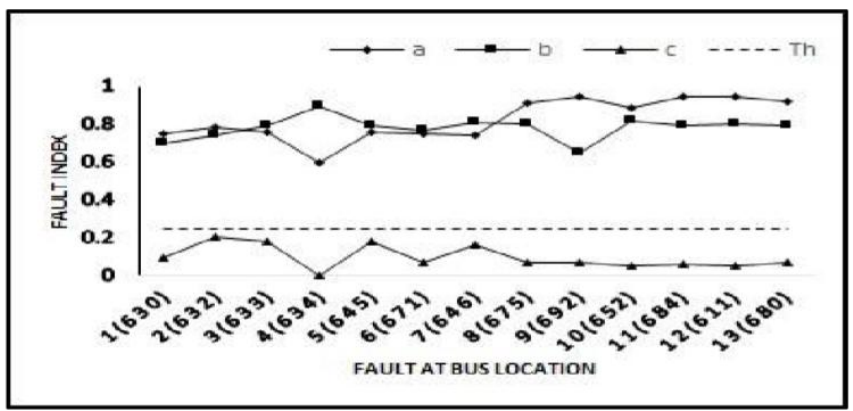

Fig.8(c): ph-'a' to ph-'b' to ground fault index for various fault nodes

\section{B. Variation of fault incidence angle:}

Level of current value and current flow directions also get change by Fault incidence angles (FIAs).Angle of fault occurrence varies from $0^{\circ}$ to $150^{\circ}$ with $30^{\circ}$ shift and tested the proposed technique. Figure. 9 displays deficiency list variety in fault occurrence angles for different issues. If there should arise an occurrence of ph-'a' to ground shortcoming, the flaw record of ph-A is constantly more the limit and those of ph- 'b' the limit and those of ph-' $b$ ' and ph-'c' are not exactly the edge if there should be an occurrence of ph-'a' to ground issue, for all the shortcoming areas. Figs. $8 \mathrm{~b}$ and $\mathrm{c}$ demonstrate that the issue list of ph-' $a$ ' and ph-' $b$ ' are more prominent than the limit and that of ph-' $\mathrm{c}$ ' is not exactly the edge if there should arise an occurrence of ph-' $a$ ' and ph'b'shortcoming and stages ph-'a' and ph-'b' to ground flaw, for differing deficiency areas. From Fig. 8d, for threestage flaw, it very well may see issue files of all the three stages are more noteworthy than limit, for various issue areas.

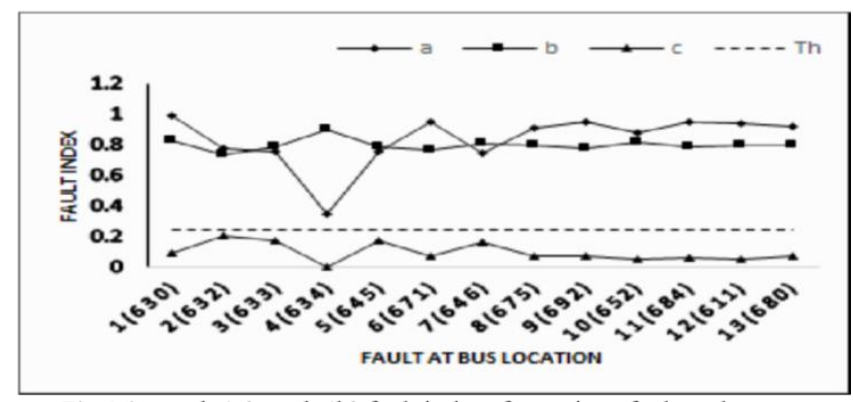

Fig.8(b): ph-'a' to ph-'b' fault index for various fault nodes

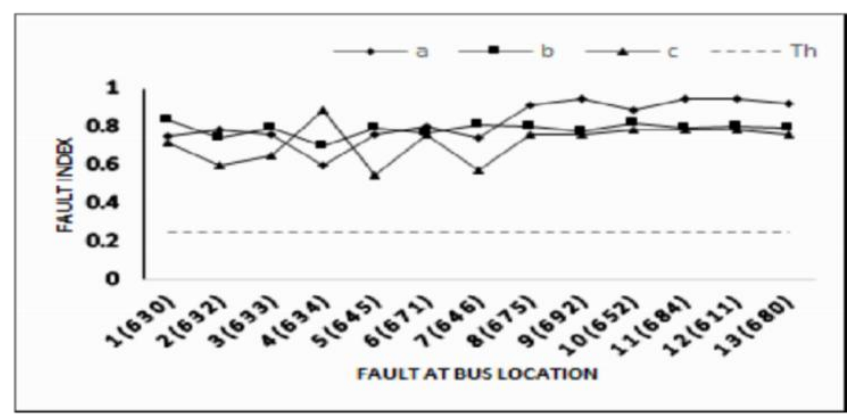

Fig.8(d): Three phase fault index at different fault locations

and ph-'c' are not exactly the edge, for different in fault occurrence angles, as appeared in figure $9 \mathrm{a}$. figure $9 \mathrm{~b}$ and $\mathrm{c}$ delineate deficiency record of ph-' $a$ ' and ph-'b' are more noteworthy than the limit for ph-'a' to ph-' $b$ ' shortcoming and ph-' $a$ ' and ph-'b' to ground issue, individually. Figure 9d shows the deficiency files of three-phases than edge in case of a three-stage shortcoming. 


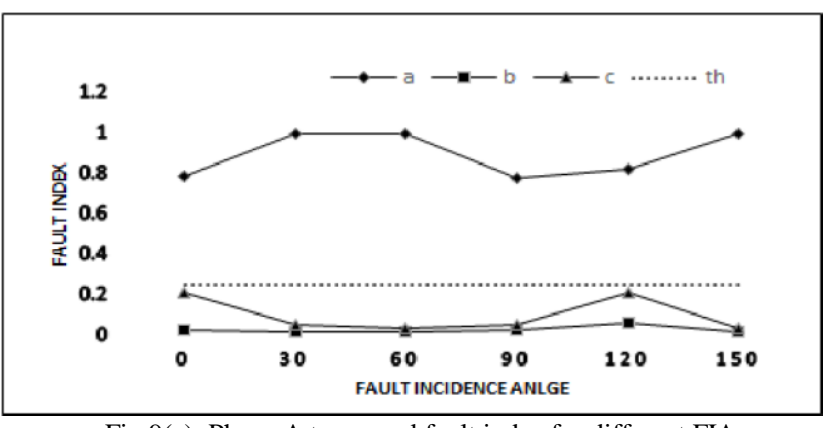

Fig.9(a): Phase-A to ground fault index for different FIA

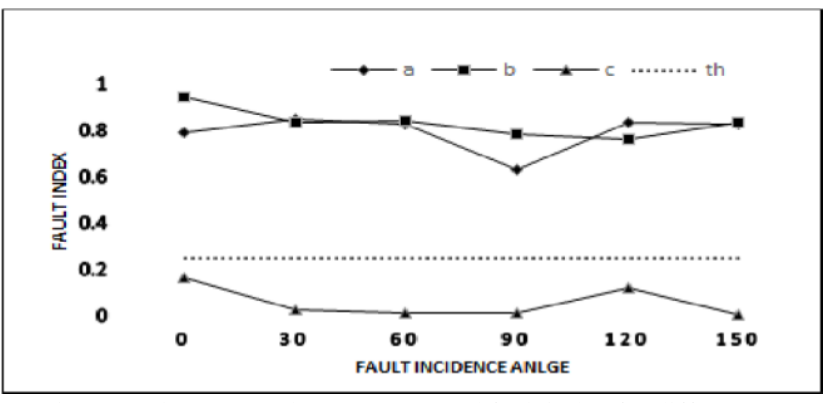

Fig.9(c): Phase-A to Phase-B to ground fault index for different FIA

\section{C.VARAITION IN WIND SPEED:}

Wind speed variety will changes the breeze ranch age control which influences the exhibition of the assurance calculation. Henceforth the strategy proposed tried for various breeze speed conditions from $9 \mathrm{~m} / \mathrm{s}$ to

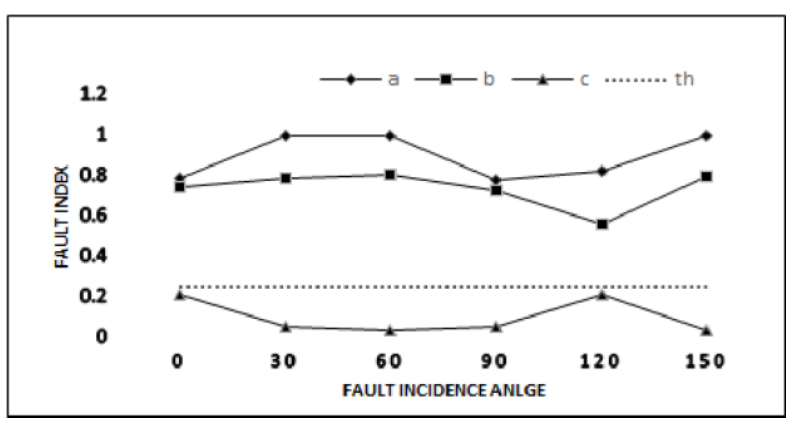

Fig.9(b): Phase-A to Phase-B fault index for different FIA

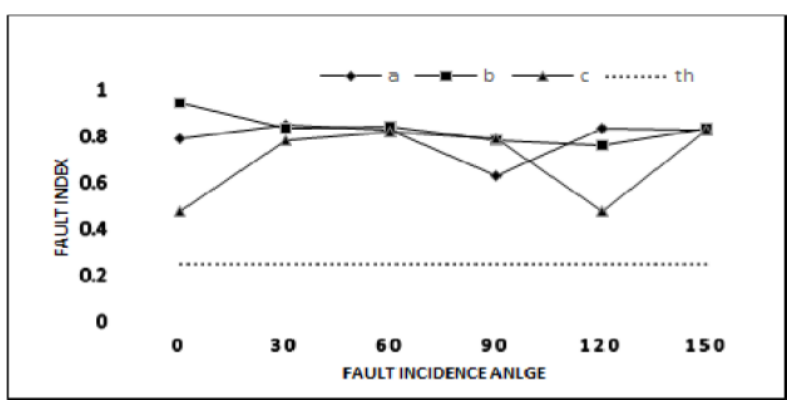

Fig.9(d): Three phase fault index for different FIA

$21 \mathrm{~m} / \mathrm{s}$ in ventures of $3 \mathrm{~m} / \mathrm{s}$. Results showed in figures 10(a),10(b) and 10(c) are for various flaws at Bus 632 with varieties in wind speed from $9 \mathrm{~m} / \mathrm{s}$ to $21 \mathrm{~m} / \mathrm{s}$. Here it clear that the proposed method not influenced by the breeze speed varieties in separating the

strange condition for a fault.

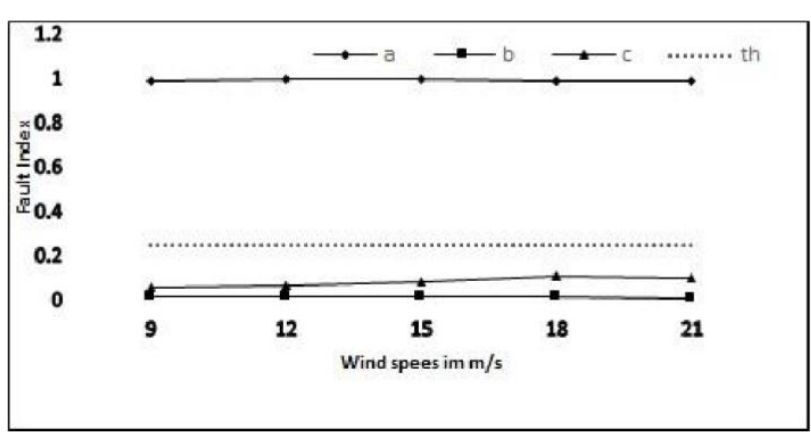

Fig 10(a) Phase-A to ground fault index for different wind speeds.

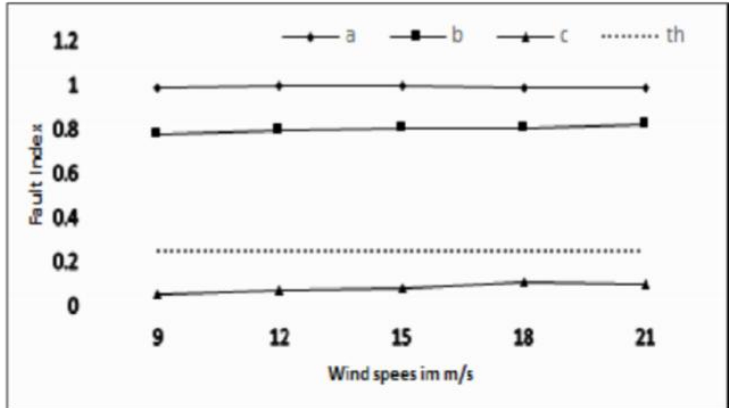

Fig 10(b) Phase -A to Phase- B fault index for different wind speeds.

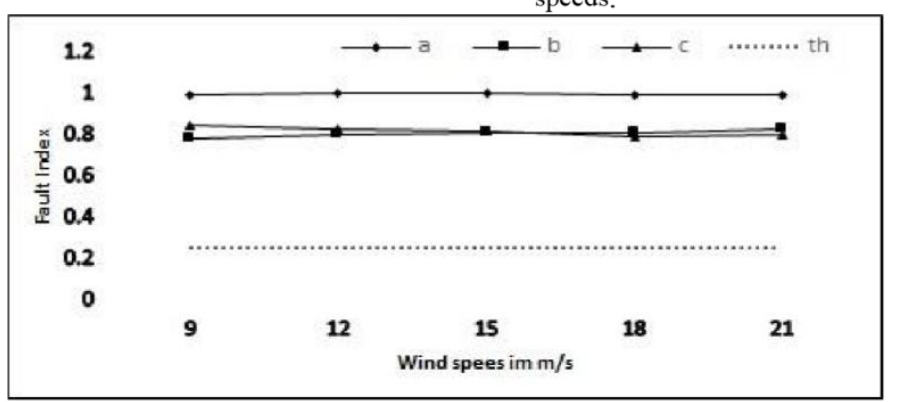

Fig 10(c) Three phase fault index for different wind speeds

\section{D.CHANGE IN CONNECTED WIND FARM CAPACITY:}

Change in capacity of connected wind farm will likewise influence the exhibition of the insurance calculation. Thus the method proposed tried for various breeze farm generations of $1.5 \mathrm{MW}$ to $9 \mathrm{MW}$ in steps of $1.5 \mathrm{MW}$. Outcomes pictured in figures $11(\mathrm{a}), 11(\mathrm{~b})$ and 11(c) are for different faults with variations in wind farm generations. Figures show the robustness of the proposed method is differentiating the abnormal conditions even the connected wind farm changes it generating capacity. 


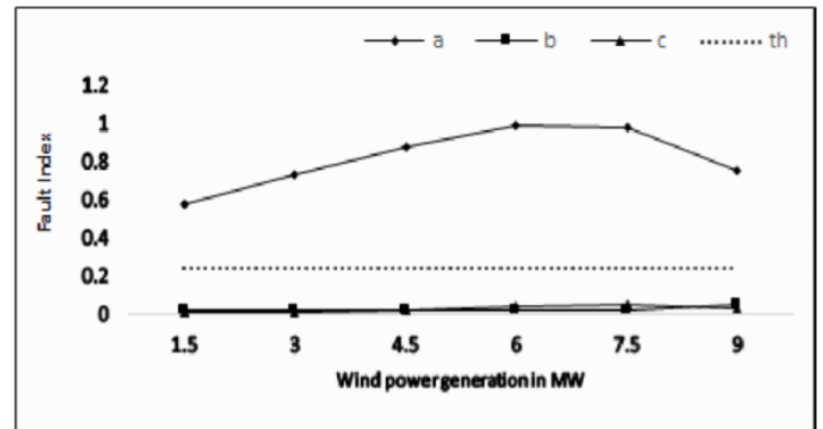

Fig 11(a) Phase-A to ground fault index for different wind farm generations.

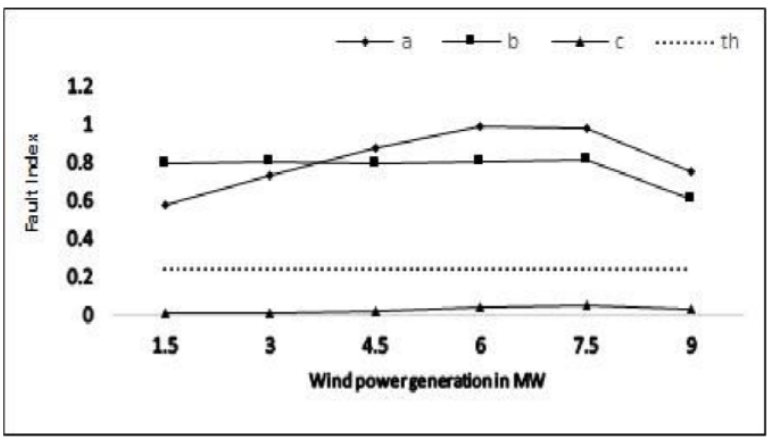

Fig 11 (b) Phase-A to Phase-B fault index for different wind farm generations.

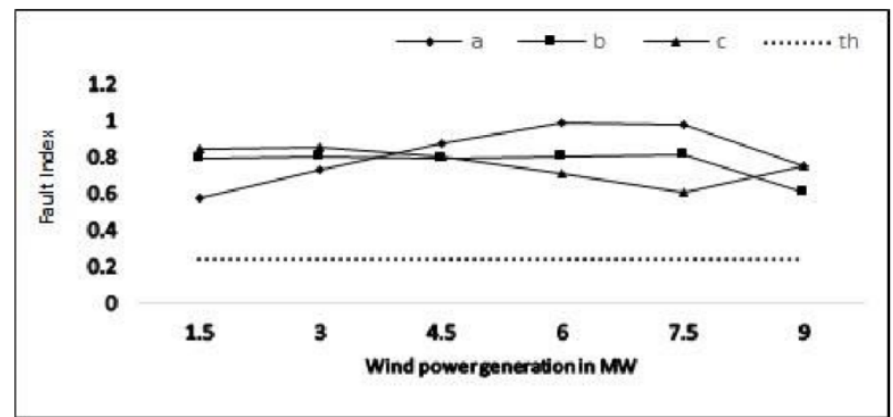

Fig 11(c) Three Phase fault index for different wind farm generations.

\section{E.WIND FARM CONNECTING LOCATION:}

The location of wind farm connection to the distribution system is also affects the fault current levels and fault paths, hence the technique also tested for wind farm connection at different distribution bus locations
B680, B652, B611, B675, B646, B671.Figures 12(a),12(b) and 12(c) indicates the change of fault index for single phase to ground,

phase to phase and 3-ph faults respectively. Figures reveals the effectiveness of the technique in discriminating abnormal condition.

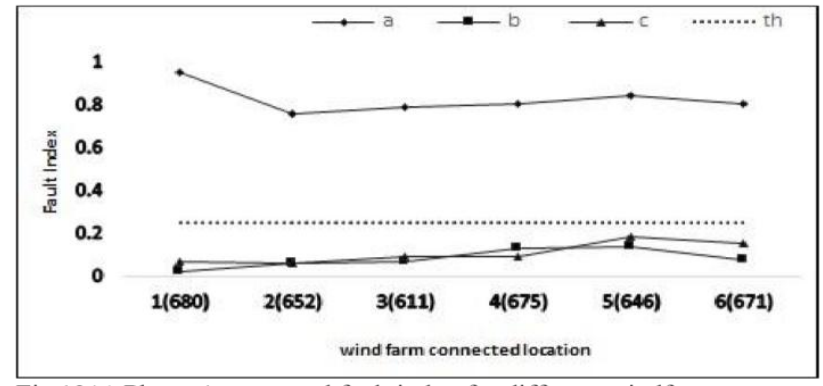

Fig 12(a) Phase-A to ground fault index for different windfarm connected locations

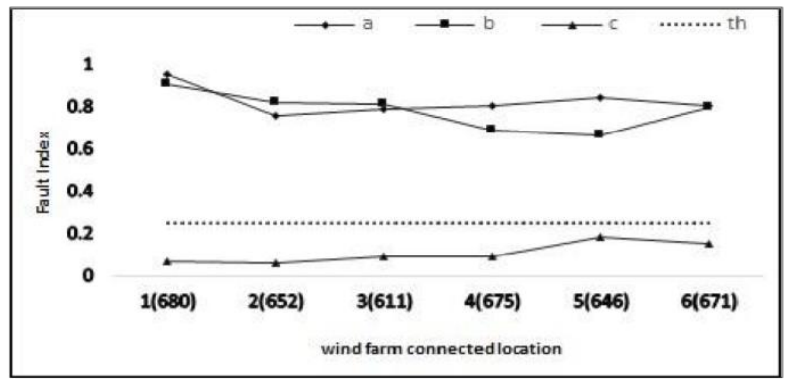

Fig 12(b) Phase-A to phase-B fault index for different wind farm connected locations

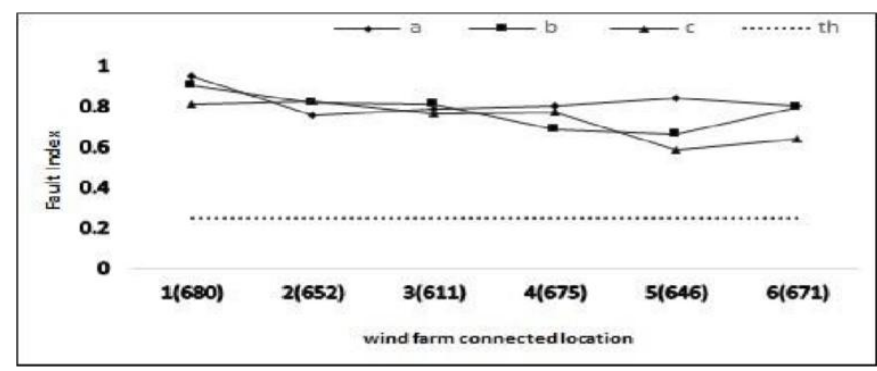

Fig 12(c) 3- Ph fault index for various wind farm connected locations 


\section{CONCLUSION}

Suggested strategy was effectively tried to detect and classified the all types of faults in a wind farm connected distribution system. Distinguishing proof and arrangement of faults have been accomplished utilizing a waveletalienation coefficient s of differential currents. Fault identification was successfully done in half cycle data of current samples. Robustness of technique was also tested with location of change in fault, fault incidence angle, wind speed, wind farm connected location and wind farm generating capacity for all types of shunt faults. All the results obtained are reveals reliability of technique in discriminating the abnormal condition of the system. It has been established wavelet-alienation based technique not effected by change in location of fault, angle of fault inception, wind speed, wind farm connected location and wind farm generating capacity in view of protection of the distribution system. The technique observed to be quick, exact and dependable for assurance of distribution system in presence of wind based DGs.

\section{REFERENCES:}

[1] R, Gokila, Arunkumar P, Deepakkumar S, Athul Ravi, And Sakthivel S. "Home Automation Using Smart Mirror With Raspberry Pi." international journal of communication and computer $\begin{array}{llll}\text { technologies 7.supplement } & 1 & \text { (2019), } & 33-34 .\end{array}$ print. doi:10.31838/ijccts/07.sp01.08

[2] P. Barker and R.W. DeMello, "Determining the impact of DG on power systems, radial distribution," in Proc. IEEE Power Eng. Soc. Summer Meeting, 2000, pp. 1645-1656.

[3] A. Girgis and S. Brahama, "Effect of distributed generation on protective device coordination in distribution system," in Proc. Large Engineering Systems Conf. Power Engineering, Jul. 2001, pp. 115-119.

[4] Yavuz Ates, Ali Rifat Boynuegri , Mehmet Uzunoglu et el "Adaptive Protection Scheme for a Distribution System Considering Grid-Connected and Islanded Modes of Operation" Energies 2016, 9 , 378; www.mdpi.com/journal/energies

[5] C. Mozina, "Impact of green power distributed generation," IEEE Ind.Appl. Mag., vol. 16, no. 4, pp. 55-62, Jul./Aug. 2010.

[6] J. C. Gomez and M. M. Morcos, "Coordinating overcurrent protection and voltage sags in distributed generation systems," IEEE Power Eng. Rev., vol. 22, no. 2, pp. 16-19, Feb. 2002.

[7] Abdul Gafoor Shaik and P.V. Ramana Rao, "Wavelet based fault detection, classify cation and location in transmission lines," in Proc. 2006 IEEE power and Energy Conference, pp. 114-118.

[8] M. E. Masoud and M. M. A. Mahfouz, "Protection scheme for transmission lines based on alienation coefficients for current signals," IET Gener. Transm. Distrib, vol. 4, pp. 1236-1244, 2010.

[9] S. M. Brahma, A. A. Girgis, "Development of adaptive protection scheme for distribution systems with high penetration of distributed generation,” IEEE Trans. Power Delivery, vol. 19, no. 1, pp. 56-63, Jan. 2004

[10] P. Mahat, C. Zhe, B. Bak-Jensen, and C. L. Bak, "A simple adaptive overcurrent protection of distribution systems with distributed generation," IEEE Trans. Smart Grid, vol. 2, no. 3, pp. 428-437, Sep. 2011.

[11] I. Chilvers, N. Jenkins, and P. Crossley, "Distance relaying of 11 $\mathrm{kV}$ circuits to increase the installed capacity of distributed generation," Proc. Inst. Elect. Eng., Gen., Transm. Distrib., vol. 152, pp. 40-46,2005.

[12] G. Tang and M. R. Iravani, "Application of a fault current limiter to minimize distributed generation impact on coordinated relay protection," presented at the Int. Conf. Power Syst. Transients, Montreal, QC, Canada, 2005.

[13] A. Agheli, H. A. Abyaneh, R. M. Chabanloo, and H. H. Dezaki, "Reducing the impact of DG in distribution networks protection using fault current limiters," in Proc.4th Int. Power Eng. Optimiz. Conf., 2010, pp. 298-303.

[14] W. El-khattam and T. S. Sidhu, "Resolving the impact of distributed renewable generation on directional overcurrent relay coordination: A case study," IET Renew. Power Gen., vol. 3, pp. 415-425, 2009.
[15] M. Baran and I. El-Markabi, "Adaptive over current protection for distribution feeders with distributed generators," in Proc. IEEE Power Eng. Soc. Power Syst. Conf. Expo., 2004, pp. 715-719.

[16] N. Schaefer, T. Degner, A. Shustov, T. Keil, and J. Jaeger, "Adaptive protection system for distribution networks with distributed energy resources,"presented at the 10th IET Int. Conf. Develop. Power Syst. Protect., Manchester, U.K., 2010.

[17] H. Cheung, A. Hamlyn, Y. Cungang, and R. Cheung, "Network-based adaptive protection strategy for feeders with distributed generations," in Proc. IEEE Canada Elect. Power Conf., 2007, pp. 514-519.

[18] I. Abdulhadi, F. Coffele, A. Dysko, C. Booth, and G. Burt, "Adaptive protection architecture for the smart grid," in Proc. 2nd IEEE PowerEng. Soc.Int. Conf. Exhibit. Innovative Smart Grid Technol., 2011, pp.1-8.

[19] Scheme for Distributed Systems with Distributed Generation" In Proceedings of the IEEE Power and Energy Society General Meeting, San Diego, CA, USA, 24-29 July 2011.

[20] André De Souza Gomes, Marcelo Azevedo Costa, Thomaz Giovani Akar de Faria, and Walmir Matos Caminhas, "Detection and classification of faults in power transmission lines using functional analysis and computational ntelligence," IEEE Trans. Power Delivery, vol. 28, pp. 14021413, Jul. 2013.

[21] F. B Costa, B. A. Souza, and N. S. D. Brito, "Effects of the fault inception angle in fault-induced transients," IET Gener. Transm.Distrib, vol. 6, pp. 463-471, 2012.

[22] Ravi Kumar Goli, Abdul Gafoor Shaik and SS Tulasi Ram, "A transient current based double line transmission system protection using fuzzywavelet approach in the presence of UPFC," International Journal of Electrical Power \& EnergySystems, pp. 91-98, 2015.

[23] Shaik Abdul Gafoor, Sandeep Kumar Yadav, Pasunoori Prashanth and T Vamshi Krishna,"Transmission Line Protection Scheme Using Wavelet Based Alienation Coefficients", in Proc. 2014 IEEE International Conference Power and Energy, pp.32-36.

[24] Francisco Martin and Jose A. Aguado, "Wavelet-based ANN approach for transmission line protection." IEEE Trans. Power Delivery, vol. 18, pp. 1572-1574, Oct. 2013.

[25] Rao, P. Venugopal, Shaik Abdul Gafoor, and C. Venkatesh. "Detection of transmission line faults by wavelet based transient extraction." International Journal on Electrical \& Power Engineering 2 (2011): 42-46.

[26] R.Abd Allah "Protection scheme for transmission lines based on correlation coefficients "IJEPE,Science publishing Group, vol. 3 issue2, pp. 93102, 2014.

[27] Singh, M.; Panigrahi, B.K.; Abhyankar, A.R.; Das, S. "Optimal Coordination of Directional Over-current Relays Using Informative Differential Evolution Algorithm”. J. Comput. Sci. 2014, 5, 269-276.

[28] El-Zonkoly, A.M. "Fault Diagnosis in Distribution Networks with Distributed Generation". Electr. Power Syst. Res. 2011, 81, $1482-1490$.

[29] Bhuvnesh rathore, Abdul gafoor shiak "Fault detection and classification on transmission line using wavelet based alienation algorithm" ISGT-Asia 2015, At Bangkok, Thailand

[30] Rao, B. Venkateswara, et al. "Optimal power flow by Newton method for reduction of operating cost with SVC models." 2009 International Conference on Advances in Computing, Control, and Telecommunication Technologies. IEEE, 2009.

[31] Shaik, Abdul Gafoor, and Om Prakash Mahela. "Power quality assessment and event detection in hybrid power system." Electric Power Systems Research 161 (2018): 26-44.

[32] Durga Prasad Bandaru and Shaik, Abdul Gafoor, "Wind farm connected distribution system protection using wavelet-alienation coefficient technique."” 2018 3rd International Conference for Convergence in Technology (I2CT),IEEE Bombay section,paperID-316,April 2018. 